\title{
IMPROVING PROCESS OF QUOTATION CREATION THROUGH VALUE STREAM MAPPING AND SIMULATION
}

\author{
Sremcev, N.; Stevanov, B.; Lazarevic, M.; Mandic, J.\#; Tesic, Z. \& Kuzmanovic, B. \\ University of Novi Sad, Faculty of Technical Sciences, Trg Dositeja Obradovica 6, Novi Sad, Serbia \\ E-Mail: jovan.mandic@uns.ac.rs ( ${ }^{\#}$ Corresponding author)
}

\begin{abstract}
Nowadays many companies are applying the lean philosophy and value stream mapping (VSM) tool to eliminate and reduce losses and show possible places for further implementation of the lean concept. Since the system change takes place as a consequence, it is very useful to confirm the future system design performance before the actual implementation. This paper presents an application of VSM and computer simulation in a company for manufacturing and distribution of heating, cooling and neutral equipment for catering and trade industry. To improve the quotation creation process, the product configuration system is introduced. The performance of the new system design was confirmed using the discrete event simulation. Simulation results show several performance improvements. Conducted simulation experiments emphasize the better performance of new system design in terms of the accepted quotations, resource utilization, delivery time, work in process, non-value-added time and number of required operators.

(Received in April 2019, accepted in October 2019. This paper was with the authors 1 month for 1 revision.)
\end{abstract}

Key Words: Value Stream Mapping (VSM), Lean Concept, Product Configuration System, Process Improvement, Simulation

\section{INTRODUCTION}

In the last two decades, companies have experienced a steady increase in customer demands for customized products, making the product configuration one of the crucial tasks in the quotation creation process. Many products exist in different variants or configurations that are offered to customers. The customers had become aware of more available alternatives, making them less likely to buy a product that does not fully meet their specific needs. For the companies to be competitive on the market, they must deal with the increase in product variety [1]. This means that production companies must shorten the time of product configuration according to customer demands. In situations like these, production companies can use the product configuration systems that enable reduction of time needed to create a quotation which will be accepted by the customer $[2,3]$.

Since the introduction of the product configuration system represents a big change and impacts other processes in a production system, each of the processes of interest should be mapped analysed and adapted for the change. This approach has often been practiced within a lean philosophy [4], which is the standard production approach of this century [5]. Theoretically, the lean approach can be applied in any industry [6], and its ultimate goal is to eliminate or decrease waste and deliver value to customers [7]. The Lean concept relies heavily on mapping tools for analysing the current system situation where VSM plays an important part. VSM is a mapping tool for the set of activities (value-added as well as nonvalue-added) that are necessary to bring the product from raw material to the finished product for the customer [8]. VSM can be applied in various domains including production [9], industrial logistics [10], software development [11], pharmaceutical [12], health care [13] and service industry $[14,15]$.

Some studies have achieved great results using only the value stream mapping tool [16], however, some VSM limitations are evident, as Carvalho et al. [17] argue that VSM is not able to represent multiple process routes, to visualize and measure all types of waste. This is 
the main reason why most authors combine VSM and simulation software [18-24] or combine other lean tools with simulations as it's been confirmed in practice [25].

By reviewing literature not too many research papers have been found on the application of VSM methodology for the processes of products configuration and products quotation creation. In this paper, a new constructive approach is proposed for a problem that explores certain specific characteristics of the customized product quotation creation process. In particular, when new customer demand is processed, the proposed approach analyses the activities needed for creating the quotation, to reduce the total time needed to complete the customer order. The presented approach improves the efficiency of the quotation process for the customized product through the product configuration system application. Since the VSM is a method of instantaneous observations, it cannot always provide the exact value for the parameters of interest (in this case the number of repetitions for a quotation rework). The presented method in this paper uses the computer simulation to check what happens in the process when the average number of rework is done in the quotation creation process. In that manner, the process simulation corrects the results obtained by VSM, by enabling the decision-maker to look more broadly at the existing system problems.

The remainder of this paper is organized as follows. In Section 2, the research methodology has been explained. Section 3 shows the case study and analysis of the quotation creation process. Section 4 presents the discussion of experimental results, while Section 5 presents conclusions on the practical and theoretical implications of this study as well as limitations and appropriate directions for further research.

\section{METHODOLOGY}

The research was carried out in a company for the production of cooling and thermal devices from the Republic of Serbia. The research aimed to improve the company's business through the application of the product configurator [26] in the process of quotation creation for the customer.

The first step of implementing the company business process improvement was to map the process of quotation creation for the customer and to create the value stream map (VSM) diagram as described in [27]. Through the VSM, the process itself was visualized, as well as total lead time, value-added time, work in process (WIP), and information relevant to each workplace (change over, cycle time, uptime, shifts, etc.). Then another VSM was created showing the desired future (TO-BE) state or system state with the product configuration system in use. In the next step, the simulation models were built, covering all process steps for quotation creation, with defined parameters for entry points, activities, and decisions. Simulations were performed to confirm future system performance improvements. Simulation experiments were conducted in line with different process parameters. The results of the conducted simulation experiments enable comparison of the process performance with and without the product configuration system. If the results of the simulation confirm the data obtained through VSM and suggestions for improvement, then the physical realization of the business process improvement can be initiated according to the future VSM.

\section{CASE STUDY}

\subsection{Analysis of the quotation creation process}

Customers were classified into two groups, one that requires a simple product (only a thermal or cooling device) and second that requires complex product (consisting of two or more combined cooling and thermal devices). Based on the practical experience of the observed company and other manufacturers of refrigeration and thermal equipment in the Republic of 
Serbia, it was concluded that in the first third of the calendar year, the ratio is $90 \% / 10 \%$ in favour of the requirements for simple products, because it is the time when most small businesses (bakeries, mini dairies, grocery stores) invest in their improvements. By the middle of the year, this ratio becomes $63 \% / 37 \%$ in favour of requests for simple products and finally at the last 4 months of the year the ratio is $90 \% / 10 \%$ in favour of the requests for complex products, because this is the time of the year when most large companies (chains, hotel chains, public kitchens, etc.) make big investments. In the existing system (AS-IS process state) the customer request is received and recorded. For the received request, the budget and the detailed quotations should be created. Budget quotation contains no product visualization for the requested product but includes the list of parts and subassemblies the product will contain, the indicative price for the requested product and the expected delivery date. For the budget quotation, the control of documentation needs to be done in order to check if the created quotation corresponds to the recorded customer requests. If the customer is satisfied with the budget quotation, it is further elaborated through the detailed quotation. Otherwise, the budget quotation should be changed due to customer requests.

The detailed quotation is created through several tasks:

- Changing the part drawing designs - changing the existing CAD drawings for the parts due to customer requests.

- Communication with suppliers for other parts - checking the available quantities and the procurement prices at suppliers.

- Designing the subassemblies - creating the subassemblies drawings with the appropriate CAD software, defining the electronic subassembly for the product, and creating the necessary calculations (a specialist for the specific product makes the calculations).

- Final product configuration - design and work simulation of the final product with the CAD software.

- Final price calculation - product documentation is created and product price is calculated (the price is calculated by using the data from the product documentation).

Next, the detailed quotation is sent to the customer. If the customer is satisfied with the detailed quotation, the company can start with the production process. Otherwise, the rework is needed. The rework tasks include all the tasks previously mentioned, starting with the change of product design drawings and finishing with the final price recalculation. The reworked detailed quotation is again sent to the customer, who decides whether to accept it.

Every week, the company receives approximately 120 requests. Concerning that, 20 requests are used as daily demands. WIP was obtained as a snapshot of a regular day. Data is collected in one month period, during which the company received customer requests in the ratio of $63 \%-37 \%$ in favour of the simple products (this ratio depicts the most usual situation in the company). As shown in Fig. 1, there are 11, 9 and 6 WIP before each operation. Waiting time of WIP inventory is calculated by dividing numbers of WIP with daily orders. The sum of the waiting times presents a lead time for the quotation process [8]. In this scenario, it takes 1.3 days for the request to be processed and a quote is shipped to final customer from the moment a customer has placed an order to a company. By summarizing cycle times for each process, value-added time can be calculated, and in this case, it is $122 \mathrm{~min}$. Information flow can be seen from Fig. 1 as well. A customer is connected with few processes to evaluate quotation and place an order. Orders were sent electronically and by company visits.

The quotation process analysis has shown that the rework is needed several times before the final quotation is accepted. Approximately $95 \%$ of initial quotations need rework two times. Twelve complex activities, the person responsible for each of them and the accompanying documents are identified. Also, the activities durations are calculated and the activities are divided into value-added and non-value-added. The order of activities is defined 
and the average number of activity repetitions is determined (certain activities are repeated until a satisfactory quotation is reached for the customer, as presented in Fig. 1).

By analysing the activity of the given order for the cooling-thermal device, the repetition loop was detected from the $6^{\text {th }}$ to the $2^{\text {nd }}$ activity (from the customer decision for budget quotation to the manual product configuration). It's been observed the repetition loop from the $12^{\text {th }}$ to the $7^{\text {th }}$ activity (from the customer decision for the detailed quotation to the changing part drawing design) several times (practice shows that an average is three times passes through the mentioned repetitive loop until the moment when the customer accepts a detailed quotation offer).

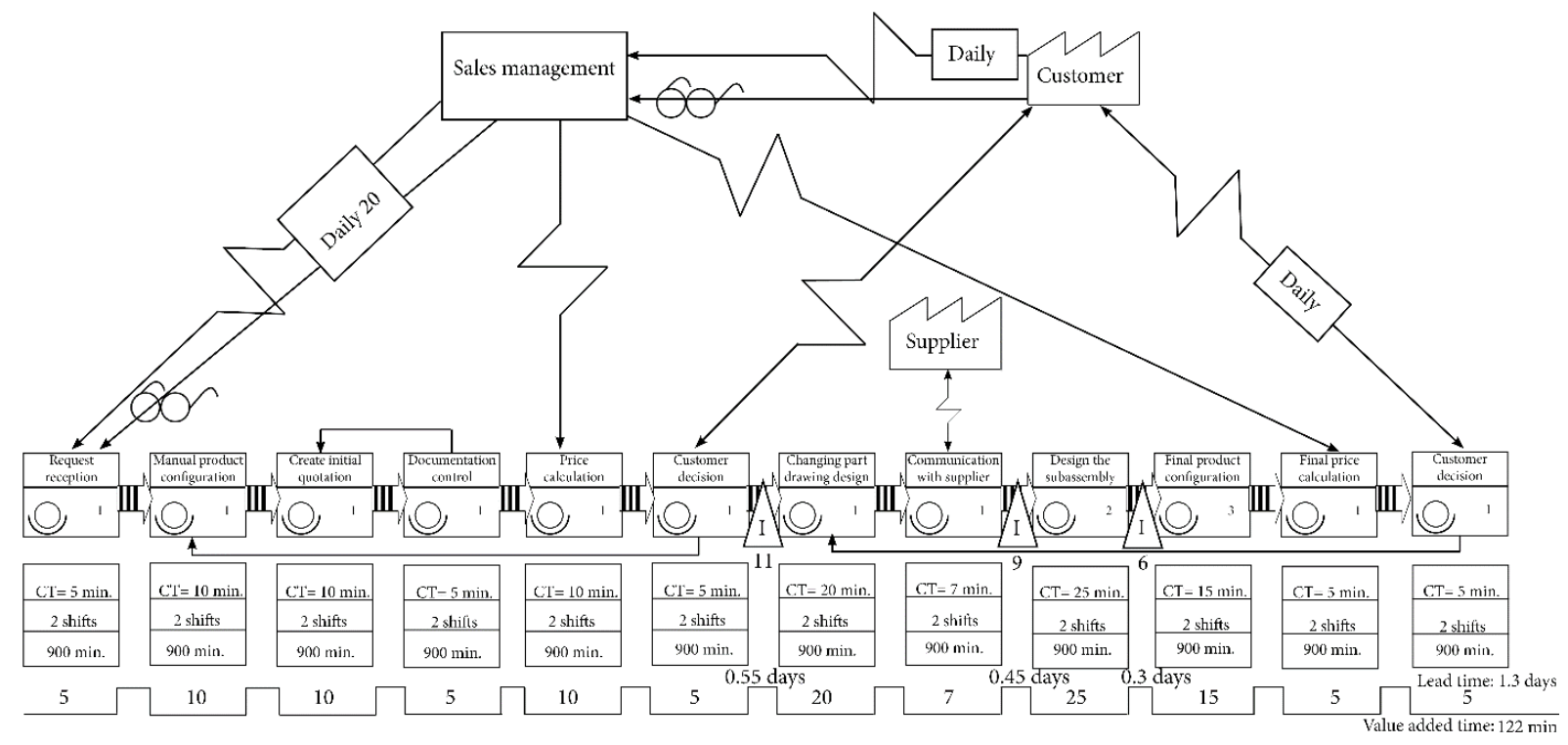

Figure 1: Current Value stream map for quotation creation process.

Based on the information carrier, duration time and the repetition loop, a proposal for improving the activity of the quotation execution process was created, replacing the manual configurations of the products with the configuration system (TO-BE process state). The configuration system would allow the returned quotation to be corrected only once through activities that require the most time, and the repetition loop for returned quotation is retained at the initial activities of the process (eliminating the return loop for a detailed offer), as shown in Fig. 2. This would significantly save time and costs for the quotation creation process (lead time could be reduced to 4.5 hours and the value-added time to 95 minutes).

In the new system setup, when a request is received, the configuration task is initiated. The number of process activities has been reduced from 12 to 10 . With the usage of configuration software, the product is configured. When finished, the product configuration is checked against the customer requests. If needed, changes to product configuration are done. The budget quotation is formed containing different data:

- The product price which is based on the parts and subassemblies selected previously during the configuration activity.

- Visualized product with the configuration system.

- List of parts and subassemblies is also accessible for the customer.

- The information when the product will be finished.

If the customer doesn't accept the budget quotation, the configuration system is used for applying the necessary changes on the product's design (this can also cause the change in the product price). Otherwise, the product details can be further elaborated. The budget quotation contains enough information for the customer, so the further work does not require much time, contrary to the case when the configuration system is not used. 


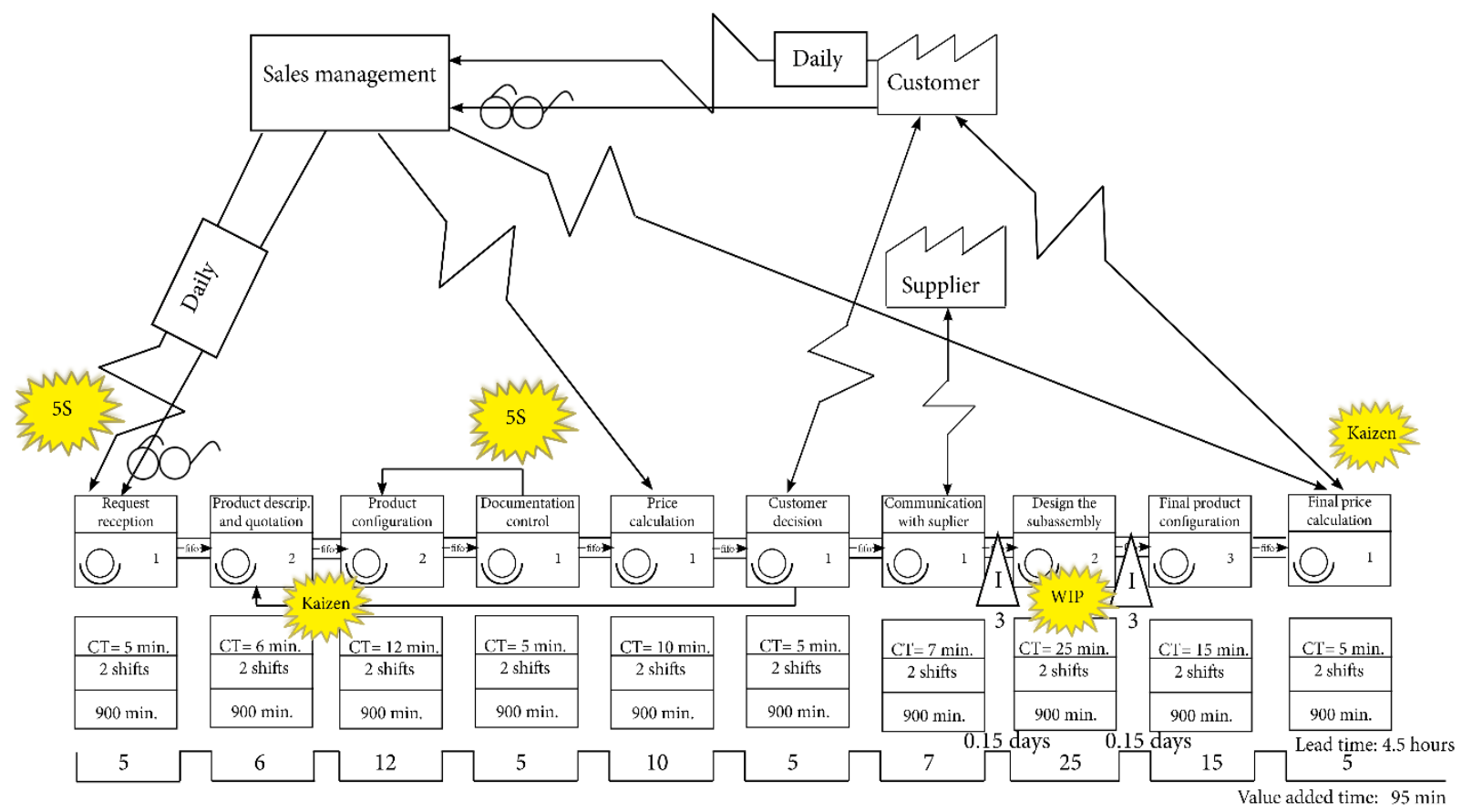

Figure 2: Future Value stream map for quotation creation process.

Further activities are the same as in the environment without the configuration system (communication with suppliers for other parts, designing the subassemblies, final product configuration, and final price calculation). Depending on the amount of created product information during the configuration activity, some of the mentioned activities can be skipped or significantly shortened in time, without the need for the rework. For example, if all the parts and subassemblies are defined previously in the configuration system, they do not have to be designed from the ground up. Only in the cases when the existing parts or subassemblies are not defined previously in the configuration activity, or when new parts or subassemblies need to be developed, the engineers do the part/subassembly design and create the necessary documentation.

\subsection{Simulation of the quotation creation process}

Several simulation experiments were done using the Arena software. By using Arena, resource utilization, work in progress and throughput can be traced and analysed [28]. Every experiment consists of two simulations of the quotation process, first without the application of the product configuration system and the second one with the use of the product configuration system. In each experiment, every simulation has been done for the six-day workweek, with a two eight hour shift (the shift has a 7.5 hour working time and 30 minutes of lunch break). Each experiment was done with the assumption that there could be a total of 120 customer requests received during the workweek (in reality, the number of weekly requests may vary, but 120 requests per week fit the most common situation). Simulation models were built according to the identified activities in VSM with the following setup:

- Simulation parameter for tact time of quotation reception was set to constant.

- Activities processing times were given with a triangular distribution, with most likely processing time being the average processing time identified from observations recorded in VSM.

- Rework of quotations is included in simulation models through loops with decision points for exiting the loops.

- The number of simulation replications for each experiment is 1 , for each system setup. 
In order to check the validity of the results from one replication of each simulation experiment, every simulation experiment was also run with 50 replications and the differences in the results between experiments were minor, because of the parameters setup for simulation model elements (the entry of the requests is set to constant and there is not much difference between the processing times in a triangular distribution of each activity).

Requests structure in the means of simple and complex products ratio varied from experiment to experiment, aiming to measure the improvement which resulted in the application of the product configuration system. The first experiment represents the actual situation in the company concerning the ratio between the customer requests for complex and simple products. The second and the third experiment process two potential extremes. The second experiment deals with the majority of customer requests for complex products, and the third experiment deals with the majority of customer requests that are for the simple products. Customer requests ratio for complex and simple products was set up as follows:

- First experiment: out a total of 120 received customer requests, 45 requests $(37.5 \%)$ were for complex products and 75 requests $(62.5 \%)$ were for simple products.

- Second experiment: out a total of 120 received customer requests, 108 requests (90\%) were for simple products and 12 requests $(10 \%)$ were for complex products.

- Third experiment: out a total of 120 received customer requests, 12 requests (10\%) were for simple products and 108 requests $(90 \%)$ were for complex products.

\section{RESULTS}

Experimental results represented in tables below are divided into two groups, where the first group contains results from experiments in environment settings without configurator and the second group contains the experimental results when the configurator is applied. Table I presents the number of completed quotations accepted by the customers. The results show that with the usage of the configuration system more quotations can be completed. In the first experiment, there is an increase in accepted quotations by 37 quotations $(142.31 \%)$ for simple products and by 24 quotations $(171.43 \%)$ for the complex products. In the second experiment, there is an increase in accepted quotations by 59 quotations $(134.09 \%)$ for simple products and by 5 quotations $(71.43 \%$ ) for the complex products. In the third experiment, there is an increase in accepted quotations by 5 quotations (125\%) for simple products and by 50 quotations $(333.33 \%$ ) for the complex products. With the use of product configurator, rework is mainly eliminated. With the use of product configurator, much of the product design is already presented to the customer in the early phase of the process, so there is no need to repeat the activities concerning different subassemblies design. This reflects the increase of completed quotations.

Table I: Number of completed quotations accepted by the customers (out a total of 120 received).

\begin{tabular}{|r|c|c|c|c|c|c|}
\cline { 2 - 7 } \multicolumn{1}{c|}{} & \multicolumn{2}{c|}{$\begin{array}{c}\text { Environment setting } \\
\text { without product } \\
\text { configuration system }\end{array}$} & \multicolumn{3}{c|}{$\begin{array}{c}\text { Environment setting } \\
\text { with the product } \\
\text { configuration system }\end{array}$} \\
\hline Experiment no. & 1 & 2 & 3 & 1 & 2 & 3 \\
\hline Simple products quotations (accepted/received) & $26 / 75$ & $44 / 108$ & $4 / 12$ & $63 / 75$ & $103 / 108$ & $9 / 12$ \\
\hline Complex products quotations (accepted/received) & $14 / 45$ & $7 / 12$ & $15 / 108$ & $38 / 45$ & $12 / 12$ & $65 / 108$ \\
\hline Total products quotations (accepted /received) & $40 / 120$ & $51 / 120$ & $19 / 120$ & $101 / 120$ & $115 / 120$ & $74 / 120$ \\
\hline
\end{tabular}


Average total processing time for accepted quotations (Table II) also changed with the usage of the configuration system. There is a decrease of total time in favour of the environment setup with the configuration system. The results of the first experiment show that decrease in time is $72.26 \%$ for simple product quotations and $65.55 \%$ for complex product quotations. In the second experiment, the time decreases by $84.44 \%$ for simple products and by $77.63 \%$ for complex products. In the third experiment, the time decrease is $50.85 \%$ for simple and $50.95 \%$ complex products. With the introduction of the product configuration system, the quotation process becomes at average 4 times faster for simple and 3 times faster for complex products; however, the company still fails to answer all customer requests. The number of realized quotations is 2.5 times higher than without the use of the product configuration system. Accepting configurators makes it easier for designers and salespeople. This is especially evident in the total processing time of quotations and is best reflected in the experiments that handle two extreme cases (the similar amount of time is needed to process quotations for complex products in the second experiment without the configurator and the third experiment with configurator).

Table II: Average total processing time [hours] for completed quotations accepted by the customers (out a total of 120 received).

\begin{tabular}{|r|c|c|c|c|c|c|}
\cline { 2 - 7 } \multicolumn{1}{c|}{} & \multicolumn{3}{c|}{$\begin{array}{c}\text { Environment setting } \\
\text { without product } \\
\text { configuration system }\end{array}$} & \multicolumn{3}{c|}{$\begin{array}{c}\text { Environment setting } \\
\text { with the product } \\
\text { configuration system }\end{array}$} \\
\hline Experiment no. & 1 & 2 & 3 & 1 & 2 & 3 \\
\hline Simple products quotations & 39.11 & 29.43 & 30.03 & 10.85 & 4.58 & 14.76 \\
\hline Complex products quotations & 32.54 & 20.97 & 41.79 & 11.21 & 4.69 & 20.50 \\
\hline
\end{tabular}

Average waiting time (WT), presented in Table III, is mostly shorter when the product configuration system is applied:

- In the first experiment, WT decreased for the subassembly design by $76.09 \%$ for simple products and by $74.18 \%$ for complex products. Also, for the final product configuration, WT was shortened by $78.29 \%$ for simple products and by $75.22 \%$ for complex products.

- In the second experiment, $W T$ decreased for the subassembly design by $93.92 \%$ for simple products and by $96.53 \%$ for complex products. Observing the final product configuration, WT decreased by $94.66 \%$ for simple products and by $63.11 \%$ for complex products.

- The third experiment shows that WT decreased at the subassembly design by $18.73 \%$ for simple products and by $84.9 \%$ for complex products. The WT at the final product configuration was shortened by $94.69 \%$ for simple products and by $84.41 \%$ for complex products.

Waiting times are significantly shorter when the configurator is used, and this adds to increased resource utilization. For the third experiment, the waiting time for simple product quotations is shorter for about 40 minutes when the configurator is used, but that is because the majority of quotations are for complex products and the waiting time shortened more than 6 times.

Resource utilization (Table IV) shows that the utilization of employees is mostly better when the product configuration system is used. Fewer employees are needed in the environment setting with product configuration system (there is one product design engineer less), but also there is an increase in the percent of utilization for the product specialist. 
Table III: Average waiting time [hours] for the most demanding processes.

\begin{tabular}{|l|c|c|c|c|c|c|}
\cline { 2 - 8 } \multicolumn{1}{c|}{} & \multicolumn{3}{|c|}{$\begin{array}{c}\text { Environment setting } \\
\text { without product } \\
\text { configuration system }\end{array}$} & \multicolumn{3}{|c|}{$\begin{array}{l}\text { Environment setting } \\
\text { with the product } \\
\text { configuration system }\end{array}$} \\
\hline Changing the part drawing designs simple product & 13.54 & 7.20 & 19.82 & $\begin{array}{c}\text { not } \\
\text { used }\end{array}$ & $\begin{array}{c}\text { not } \\
\text { used }\end{array}$ & $\begin{array}{c}\text { not } \\
\text { used }\end{array}$ \\
\hline Changing the part drawing designs complex product & 12.74 & 6.03 & 20.73 & $\begin{array}{c}\text { not } \\
\text { used }\end{array}$ & $\begin{array}{c}\text { not } \\
\text { used }\end{array}$ & $\begin{array}{c}\text { not } \\
\text { used }\end{array}$ \\
\hline Designing the subassemblies (simple product) & 14.93 & 12.17 & 3.63 & 3.57 & 0.74 & 2.95 \\
\hline Designing the subassemblies (complex product) & 12.86 & 9.50 & 21.13 & 3.32 & 0.33 & 3.19 \\
\hline Final product configuration (simple product) & 16.95 & 12.54 & 10.93 & 3.68 & 0.67 & 0.58 \\
\hline Final product configuration (complex product) & 13.76 & 1.03 & 20.66 & 3.41 & 0.38 & 3.22 \\
\hline
\end{tabular}

Resource named Product designer 2 is not a bottleneck, that workplace represents the position that currently has the best utilization in the system because it waits the least time to get its work done. With the introduction of the configuration system, the organization of the workflow is improved and only two product designers are required to perform the work tasks. This is especially true when the number of complex products demands increases, as the higher number of product quotations can be done with the help of the product configuration system.

Table IV: Resource utilization [\%].

\begin{tabular}{|l|c|c|c|c|c|c|}
\cline { 2 - 8 } \multicolumn{1}{c|}{} & \multicolumn{3}{c|}{$\begin{array}{c}\text { Environment setting } \\
\text { without product } \\
\text { configuration system }\end{array}$} & \multicolumn{2}{c|}{$\begin{array}{c}\text { Environment setting } \\
\text { with the product } \\
\text { configuration system }\end{array}$} \\
\hline \multicolumn{1}{|c|}{ Experiment no. } & 1 & 2 & 3 & 1 & 2 & 3 \\
\hline Chief of the sales department & 39.09 & 38.56 & 40.44 & 80.59 & 78.29 & 79.36 \\
\hline Configuration system & $\begin{array}{c}\text { not } \\
\text { used }\end{array}$ & $\begin{array}{c}\text { not } \\
\text { used }\end{array}$ & $\begin{array}{c}\text { not } \\
\text { used }\end{array}$ & 87.53 & 77.80 & 99.75 \\
\hline Electric engineer & 20.07 & 27.11 & 12.35 & 34.89 & 34.33 & 33.15 \\
\hline Procurement officer & 20.13 & 22.06 & 19.07 & 20.71 & 17.03 & 22.24 \\
\hline Product design engineer 1 & 66.90 & 56.72 & 84.81 & 73.65 & 63.85 & 86.61 \\
\hline Product design engineer 2 & 98.07 & 98.52 & 98.47 & 95.67 & 90.86 & 92.35 \\
\hline Product design engineer 3 & 30.19 & 48.06 & 18.84 & $\begin{array}{c}\text { not } \\
\text { used }\end{array}$ & $\begin{array}{c}\text { not } \\
\text { used }\end{array}$ & $\begin{array}{c}\text { not } \\
\text { used }\end{array}$ \\
\hline Product specialist & 66.24 & 88.15 & 45.21 & 95.67 & 90.86 & 92.35 \\
\hline Sales department employee & 15.35 & 12.36 & 21.09 & 14.70 & 12.41 & 21.43 \\
\hline
\end{tabular}


Table $\mathrm{V}$ shows the work in process $(W I P)$, which is the average number of requests waiting to be processed. The simulation results show that the product configuration system affects the WIP:

- Simple products - for subassembly design the WIP decreased by $62.60 \%$ in the first experiment, in the second experiment the WIP decreased by $92.74 \%$, and in the third experiment there was no WIP (this is the consequence of almost non-existent WIP in the environment setting without configuration system); for the final product configuration the WIP decreased by $55.14 \%$ in the first experiment, for the second experiment the WIP decreased by $92.06 \%$, and in the third experiment the WIP was eliminated with the product configuration system.

- Complex products - for subassembly design the WIP decreased by $67.66 \%$ in the first experiment, in the second experiment the WIP was eliminated, and in the third experiment the WIP decreased by $77.74 \%$; for the final product configuration the WIP decreased by $55.14 \%$ in the first experiment, for the second experiment there is no WIP (this is the consequence of almost non-existent WIP in the environment setting without configuration system), and the WIP decreased by $60.06 \%$ in the third experiment.

Table V: Work in process (average numbers of requests).

\begin{tabular}{|l|c|c|c|c|c|c|}
\cline { 2 - 8 } \multicolumn{1}{c|}{} & \multicolumn{3}{|c|}{$\begin{array}{c}\text { Environment setting } \\
\text { without product } \\
\text { Experiment no. }\end{array}$} & \multicolumn{2}{c|}{$\begin{array}{l}\text { Environment setting } \\
\text { with the product } \\
\text { configuration system }\end{array}$} \\
\hline Changing the part drawing designs (complex product) & 6.52 & 0.80 & 24.37 & $\begin{array}{c}\text { not } \\
\text { used }\end{array}$ & $\begin{array}{c}\text { not } \\
\text { used }\end{array}$ & $\begin{array}{c}\text { not } \\
\text { used }\end{array}$ \\
\hline Changing the part drawing designs (simple product) & 11.23 & 8.48 & 2.70 & $\begin{array}{c}\text { not } \\
\text { used }\end{array}$ & $\begin{array}{c}\text { not } \\
\text { used }\end{array}$ & $\begin{array}{c}\text { not } \\
\text { used }\end{array}$ \\
\hline Designing the subassemblies (simple product) & 8.61 & 11.98 & 0.48 & 2.78 & 0.87 & 0.31 \\
\hline Designing the subassemblies (complex product) & 4.70 & 1.14 & 13.16 & 1.52 & 0.04 & 2.93 \\
\hline Final product configuration (simple product) & 5.93 & 9.82 & 0.82 & 2.66 & 0.78 & 0.06 \\
\hline Final product configuration (complex product) & 3.15 & 0.18 & 6.76 & 1.53 & 0.05 & 2.70 \\
\hline
\end{tabular}

\section{CONCLUSION AND FURTHER WORK}

Market trends show that the complex products demands will slowly increase in the future, also confirmed in [29]. This will affect the flexibility of the enterprise to adapt the changing demands [30]. In this case, this means the increase of time for critical work operations like designing of the subassemblies and the final product configuration for the complex products. It is shown that the product configuration system shortens the total quotation lead time and improves these work operations in the means of efficiency. At the same time, the product configuration system is not easy to implement in the means of time and software costs development and integration costs. To implement the product configuration system it is necessary to analyse the company's product portfolio and the whole production process. Also, it is necessary to form the team for the configuration system implementation. All these elements can present obstacles for configuration system implementation making it not always feasible in every company. 
If a thoughtful approach to the implementation is taken and the support of top management is ensured, the product configuration system in combination with lean tools can bring significant benefits to the business processes of the company. Further research work would include implementation possibilities of other lean tools like 5S, Kaizen events and first-in-first-out (FIFO) system in the quotation creation process. To improve the customer request reception and the documentation control, the administrative procedures should be applied and the regulation of the working environment of mentioned operations should be done. The 5S tool imposes here as adequate to that. Also, kaizen events should be organized, together with operators and sales management team by using the configuration system, instead of the manual product configuration process. Kaizen events would enable bettertrained employees which can include the potential customers throughout the whole product configuration process.

\section{REFERENCES}

[1] Ezzat, O.; Medini, K.; Boucher, X.; Delorme, X. (2019). Product and service modularization for variety management, Procedia Manufacturing, Vol. 28, 148-153, doi: $\underline{10.1016 /}$ J.PROMFG.2018.12.024

[2] Kristjansdottir, K.; Shafiee, S.; Hvam, L.; Bonev, M.; Myrodia, A. (2018). Return on investment from the use of product configuration systems - a case study, Computers in Industry, Vol. 100, 57-69, doi:10.1016/J.COMPIND.2018.04.003

[3] Myrodia, A.; Kristjansdottir, K.; Hvam, L. (2017). Impact of product configuration systems on product profitability and costing accuracy, Computers in Industry, Vol. 88, 12-18, doi:10.1016/J.COMPIND.2017.03.001

[4] Bhadury, B. (2000). Management of productivity through TPM, Productivity, Vol. 41, No. 2, 240-251

[5] Rinehart, J.; Huxley, C.; Robertson, D. (1997). Just Another Car Factory? Lean Production and its Discontents, Cornell University Press, New York

[6] Womack, J. P.; Jones, D. T.; Ross, D. (1990). The Machine that Changed the World, Rawson Associates, New York

[7] Heravi, G.; Firoozi, M. (2017). Production process improvement of buildings' prefabricated steel frames using value stream mapping, The International Journal of Advanced Manufacturing Technology, Vol. 89, No. 9-12, 3307-3321, doi:10.1007/s00170-016-9306-9

[8] Rother, M.; Shook, J. (2003). Learning to See: Value-Stream Mapping to Add Value and Eliminate Muda, The Lean Enterprise Institute, Cambridge

[9] Schweizer, W. (2011). Value stream engineering - four paradigms for process design in industrial engineering, Proceedings of the $21^{\text {st }}$ International Conference on Production Research, Fraunhofer IAO, Stuttgart, 56-75

[10] Knoll, D.; Reinhart, G.; Prüglmeier, M. (2019). Enabling value stream mapping for internal logistics using multidimensional process mining, Expert Systems with Applications, Vol. 124, 130-142, doi:10.1016/J.ESWA.2019.01.026

[11] Bin Ali, N.; Petersen, K.; Schneider, K. (2016). FLOW-assisted value stream mapping in the early phases of large-scale software development, Journal of Systems and Software, Vol. 111, 213-227, doi:10.1016/J.JSS.2015.10.013

[12] Chowdary, B. V.; George, D. (2012). Improvement of manufacturing operations at a pharmaceutical company, Journal of Manufacturing Technology Management, Vol. 23, No. 1, 56-75, doi: $10.1108 / 17410381211196285$

[13] Snyder, K. D.; Paulson, P.; McGrath, P. (2005). Improving processes in a small health-care network, Business Process Management Journal, Vol. 11, No. 1, 87-99, doi:10.1108/14637150510578755

[14] Tyagi, S.; Vadrevu, S. (2015). Immersive virtual reality to vindicate the application of value stream mapping in an US-based SME, The International Journal of Advanced Manufacturing Technology, Vol. 81, No. 5-8, 1259-1272, doi:10.1007/s00170-015-7301-1

[15] Morlock, F.; Meier, H. (2015). Service value stream mapping in industrial product-service system performance management, Procedia CIRP, Vol. 30, 457-461, doi:10.1016/J.PROCIR.2015.02.128 
[16] Bal, A.; Ceylan, C.; Taçoğlu, C. (2017). Using value stream mapping and discrete event simulation to improve efficiency of emergency departments, International Journal of Healthcare Management, Vol. 10, No. 3, 196-206, doi:10.1080/20479700.2017.1304323

[17] Dinis-Carvalho, J.; Moreira, F.; Bragança, S.; Costa, E.; Alves, A.; Sousa, R. (2015). Waste identification diagrams, Production Planning \& Control, Vol. 26, No. 3, 235-247, doi:10.1080/09537287.2014.891059

[18] Esfandyari, A.; Osman, M. R.; Ismail, N.; Tahriri, F. (2011). Application of value stream mapping using simulation to decrease production lead time: a Malaysian manufacturing case, International Journal of Industrial and Systems Engineering, Vol. 8, No. 2, 230-250, doi:10.1504/IJISE.2011.041371

[19] Abdulmalek, F. A.; Rajgopal, J. (2007). Analyzing the benefits of lean manufacturing and value stream mapping via simulation: a process sector case study, International Journal of Production Economics, Vol. 107, No. 1, 223-236, doi:10.1016/j.ijpe.2006.09.009

[20] Atieh, A. M.; Kaylani, H.; Almuhtady, A.; Al-Tamimi, O. (2016). A value stream mapping and simulation hybrid approach: application to glass industry, The International Journal of Advanced Manufacturing Technology, Vol. 84, No. 5-8, 1573-1586, doi:10.1007/s00170-015-7805-8

[21] Ramnath, B. V.; Chandrasekhar, V.; Elanchezhian, C.; Vinoth, L. B. S.; Venkataraman, K. (2014). Value stream evaluation and simulation to improve material flow and productivity, Applied Mechanics and Materials, Vol. 612, 89-95, doi:10.4028/www.scientific.net/AMM.612.89

[22] Persson, F. (2011). SCOR template - a simulation based dynamic supply chain analysis tool, International Journal of Production Economics, Vol. 131, No. 1, 288-294, doi:10.1016/ j.ijpe.2010.09.029

[23] Parv, L.; Deaky, B.; Nasulea, M. D.; Oancea, G. (2019). Agent-based simulation of value flow in an industrial production process, Processes, Vol. 7, No. 2, Paper 82, 15 pages, doi: $10.3390 / \mathrm{pr} 7020082$

[24] Antonelli, D.; Stadnicka, D. (2018). Combining factory simulation with value stream mapping: a critical discussion, Procedia CIRP, Vol. 67, 30-35, doi:10.1016/J.PROCIR.2017.12.171

[25] Al-Hawari, T.; Aqlan, F.; Al-Araidah, O. (2010). Performance analysis of an automated production system with queue length dependent service rates, International Journal of Simulation Modelling, Vol. 9, No. 4, 184-194, doi:10.2507/IJSIMM09(4)2.168

[26] Hvam, L.; Mortensen, N. H.; Riis, J. (2008). Product Customization, Springer-Verlag, Berlin

[27] Rother, M.; Shook, J. (1999). Learning to See: Value Stream Mapping to Create Value and Eliminate Muda, The Lean Enterprise Institute, Brookline

[28] Patel, C. R.; Sormaz, D. N. (2012). An integrative methodology for simulation of FMS with alternate routings, International Journal of Industrial Engineering and Management, Vol. 3, No. 3, 153-161

[29] Trentin, A.; Perin, E.; Forza, C. (2011). Overcoming the customization-responsiveness squeeze by using product configurators: beyond anecdotal evidence, Computers in Industry, Vol. 62, No. 3, 260-268, doi:10.1016/J.COMPIND.2010.09.002

[30] Nikoličić, S.; Kilibarda, M.; Atanasković, P.; Duđak, L.; Ivanišević, A. (2015). Impact of RFID technology on logistic process efficiency in retail supply chains, Promet - Traffic \& Transportation, Vol. 27, No. 2, 137-146, doi:10.7307/ptt.v27i2.1539 